\title{
DA BIOPOLÍTICA À NOOPOLÍTICA: A VERDADE E A PÓS-VERDADE COMO VETORES PARA MODULAÇÃO DE FORMAS DE VIDAS SURDAS
}

\author{
FROM BIOPOLITICS TO THE NOOPOLITICS: THE TRUTH AND \\ THE POST-TRUTH AS GUIDES FOR THE MODULATION OF \\ DEAF WAY OF LIFE
}

\begin{abstract}
DE LA BIOPOLITICA A LA NOOPOLITICA: LA VERDAD $Y$ LA POST-VERDAD COMO VECTORES PARA MODULAR LAS FORMAS DE VIDAS SORDAS
\end{abstract}

Lucyenne Matos da Costa Vieira-Machado ${ }^{1}$ Reginaldo CÉlio Sobrinho

Cássio Pereira Oliveira ${ }^{3}$

${ }^{1}$ Universidade Federal do Espírito Santo (UFES), Vitória/ES-Brasil ${ }^{2}$ Universidade Federal do Espírito Santo (UFES), Vitória/ES-Brasil ${ }^{3}$ Universidade Federal do Espírito Santo (UFES), Vitória/ES-Brasil Subvenção: Coordenação do Aperfeiçoamento de pessoal de Nível Superior (CAPES)

Resumo Este texto se propõe a discutir a produção de regimes de verdades na constituição de diferentes modulações de vidas surdas. Discutimos as políticas de verdades - biopolítica - em direção às políticas de pós-verdades que constituem aquilo que Lazzarato (2006) denomina de noopolítica. Para problematizar a associação dos saberes médicos, econômicos e demográficos e seus agenciamentos no campo educacional da surdez, tomamos a governamentalidade como grade de inteligibilidade do nosso tempo. Inspirados nas teorizações foucaultianas, partimos da leitura das atas do Congresso Internacional Para o Melhoramento do Destino dos Surdos-Mudos ocorrido em Milão, na Itália, de 6 a 11 de setembro de 1880, mais conhecido como Congresso de Milão para discutir as verdades produzidas acerca dos surdos e da surdez nas proposições votadas nesse congresso. E, a partir da noopolítica como noção e da pós-verdade como vetor, discutiremos as análises realizadas por surdos pesquisadores que contribuem para a compreensão da produção de formas de vidas 
surdas. Concluímos apontando que existe uma norma flexível na contemporaneidade que se dilui, por meio dos discursos identitários, para cada grupo social e que nesse contexto de multiplicação de normalidades torna-se mais difícil reconhecer as fronteiras existentes entre o normal e o anormal.

Palavras-chave: Educação de surdos; Regimes de verdades; Biopolítica; Noopolítica.

Abstract This text aims at discussing the production of truth regimes in the formation of several modulations of deaf life. We discuss the truth politics - biopolitics - towards the post-truth politics which constitute what Lazzarato (2006) calls "noopolitics". In order to problematize the connection of medical, economic and demographic knowledge and its agency in the deaf educational field, we assumed the governmentality as an intelligibility grid of our time. Inspired on the theories of Foucault, we read minutes of the International Congress on the Education of the Deaf, held in Milan, Italy, from September 6 to 11, 1880, also known as Milan Conference. From the readings we discussed the truths produced regarding deaf people and deafness in the propositions voted during that Congress. Therefore, using noopolitics as a notion and post-truth as a guide, we will discuss the analysis performed by deaf researchers who contribute to the comprehension of the production of deaf way of life. To conclude, we point out that there is a flexible rule in contemporaneity that is diluted through identity discourses for each social group. Thus, in this context of multiplication of normality it becomes harder to recognize the borders between normal and abnormal.

Keywords: Deaf education; Truth Regimes; Biopolitics; Noopolitics.

RESUMEn Este texto propone discutir la producción de regímenes de verdades en la constitución de diferentes modulaciones de vidas sordas. Discutimos la política de las verdades - la biopolítica -, hacia las políticas de post-verdades que constituyen lo que Lazzarato (2006) llama de noopolítica. Para problematizar la asociación del conocimiento médico, económico y demográfico y sus asociaciones en el campo educativo de la sordera, tomamos la gubernamentalidad como la red de inteligibilidad de nuestro tiempo. Inspirados por las teorías de Foucault, partimos de la lectura de las actas del Congreso Internacional para la Mejora del Destino de Sordomudos, celebrado en Milán, Italia, del 6 al 11 de septiembre de 1880, más conocido como el Congreso de Milán, para discutir las verdades producidas acerca de los sordos y de la sordez en las proposiciones votadas en ese congreso. Y a partir de la noopolítica como noción y de la post-verdad como vector, discutiremos los análisis realizados por investigadores sordos que contribuyen a la comprensión de la producción de vidas sordas. Llegamos a la conclusión de que existe una norma flexible en el mundo contemporáneo que se diluye por el discurso de la identidad para cada grupo social, y que en ese contexto de multiplicación de normalidad se hace más difícil reconocer las fronteras existentes entre lo normal y lo anormal.

Palabras clave: Educación de sordos; Regímenes de verdades; Biopolítica; Noopolítica. 


\section{COMEÇANdo a CONVERSA...}

Cada sociedade tem seu regime de verdade, sua "política geral" de verdade:
isto é, os tipos de discurso que ela acolhe e faz funcionar como verdadeiros; os
mecanismos e instâncias que permitem distinguir os enunciados verdadeiros
dos falsos, a maneira como se sanciona uns e outros; as técnicas e os procedi-
mentos que são valorizados para a obtenção da verdade; o estatuto daqueles
que têm o encargo de dizer o que funciona como verdadeiro.

(Michel Foucault)

Este texto se propõe a discutir a constituição de regimes de verdades na constituição de diferentes modulações de vidas surdas. Partimos das políticas de verdades - biopolítica - em direção às políticas de pós-verdades que são aquilo que Lazzarato (2006) denomina de noopolítica.

A noopolitica, diferente da biopolítica, se fundamenta nas relações entre os indivíduos. Enquanto a biopolitica se fundamenta em uma forma vertical de organização em que o Estado impera sobre as instâncias imanentes dos indivíduos que o compõem, a noopolítica se apresenta mediante uma organização em rede, horizontal, na qual os indivíduos e suas relações sejam a base para a produção de verdades da sociedade. Nas palavras de Lazzarato (2006, p. 82-83): "Enquanto as técnicas disciplinares se organizam fundamentalmente através do espaço, as técnicas de controle e de constituição do público colocam em primeiro plano o problema do tempo e da virtualidade".

Consideramos pertinente situar, desde logo, o modo em que o texto foi pensado a fim de elucidar como compreendemos a fabricação de formas de vida em contextos sociais distintos.

Evidenciamos também que, para operar com as análises, foi necessário "entender os conceitos enquanto ferramentas com as quais golpeamos outros conceitos, o nosso próprio pensamento e a nossa própria experiência" (VEIGA-NETO, 2006, p. 80). Assim, na tessitura deste trabalho, a modulação de formas de vidas surdas foi delineada a partir de dois deslocamentos.

Vejamos o primeiro deslocamento. A noção de biopolítica nos serviu como uma lente para observar, compreender e desestabilizar o regime de verdade sobre o qual se alicerçou a constituição do ser surdo a partir do século XVIII. Nesse contexto, temos a sociedade disciplinar como grade de inteligibilidade que tem como enfoque o investimento massivo sobre a vida da população (e não do indivíduo). Veremos que nesse tipo de sociedade a medicina foi utilizada como técnica de extrair e majorar conhecimento para o Estado a fim de assegurar seu funcionamento. Paradoxalmente, foi na sociedade disciplinar que a(s) verdade(s) produzida(s) contribuiu(iram) como condição de possibilidade para o agenciamento (fortalecimento) do movimento identitário contrário à ciborguização dos surdos.

Isso nos leva ao segundo deslocamento. A partir dos agenciamentos provenientes da sociedade disciplinar, a identidade se molda como uma norma do nosso tempo. Logo, o contexto social atual exigiu, nessa empreitada, que operássemos com a noção de noopolítica como ferramenta analítica. $\mathrm{O}$ investimento sobre o corpo, característico do século 
XVIII, passa por um refinamento, bem como, por um regime de verdade. A noção de políticas de pós-verdade torna-se o vetor que orienta nossa problematização em tempo de sociedade de controle. Nessa grade de inteligibilidade, a modulação de formas de vidas surdas deixa de ser restrita às instituições disciplinadoras e passa a ter o pensamento como lócus de empreendimento.

Desse modo é que, imbuídos pela e na compreensão de que vivemos em um tempo de políticas de pós-verdades (noopolítica), importante citar os acontecimentos e construções epistemológicas relacionadas aos regimes de verdades sobre surdos e sobre a surdez que foram produzidas a partir das proposições do Congresso Internacional Para o Melhoramento do Destino dos Surdos-Mudos, ocorrido em Milão, na Itália, de 6 a 11 de setembro de 1880, que ficou conhecido como Congresso de Milão.

Escolhemos propor a leitura do Congresso Internacional de Milão, pois entre os fatos históricos no campo da educação de surdos tal evento merece destaque. Apesar de se apresentar como uma memória saturada, ou mesmo aparentar uma espécie de "excesso de memória", pouco se questiona sobre os efeitos de sentidos construídos nos distintos enunciados que se capilarizam no tecido social e trafegam em diferentes materialidades discursivas na educação dos surdos.

Entre outros congressos com a finalidade de discutir a educação de surdos realizados no final do século XIX, o Congresso de Milão foi marcado por delinear os rumos e procedimentos a serem adotados na educação de pessoas surdas na Modernidade. Nesse evento, foram elencadas maneiras de ver, educar e governar o corpo surdo, seguindo premissas de visões provenientes do campo da medicina e estabelecendo um processo de normalização dos surdos por meio da oralidade.

Nos arriscamos a olhar para esse documento-monumento mais uma vez (ou mais de uma vez) com outras lentes. Não mais para dentro dele, mas ao entorno, dando uma passeada nos saberes que constituem a Modernidade e que produziram verdades relativas ao melhor método para a educação dos surdos. Tal método produz, tão logo seja possível, outras formas de subjetivação de vidas surdas. Na busca de uma análise do documento como monumento, as ponderações de Le Goff (2013, p. 485) nos parecem bastante pertinentes, especialmente quando o autor nos dirige os seguintes apontamentos:

\footnotetext{
O monumento tem como características o ligar-se ao poder de perpetuação, voluntária ou involuntária, das sociedades históricas (é um legado à memória coletiva) e o reenviar a testemunhos que só numa parcela mínima são testemunhos escritos. [...] $\mathrm{O}$ documento não é qualquer coisa que fica por conta do passado, é um produto da sociedade que o fabricou segundo as relações de forças que aí detinham um poder. Só uma análise do documento enquanto monumento permite a memória coletiva recuperá-lo e ao historiador usá-lo cientificamente, isto é, com pleno conhecimento de causa.
}

Para problematizar a associação dos saberes médicos, econômicos e demográficos e seus agenciamentos no campo educacional da surdez, tomamos a governamentalidade como grade de inteligibilidade do nosso tempo. 
De acordo com Castro (2016), "Foucault utiliza o termo 'governamentalidade' para referir-se ao objeto de estudo das maneiras de governar" (CASTRO, 2016, p. 190). Para Foucault, a 'governamentalidade' diz respeito a um domínio marcado pela "análise de formas de racionalidade, de procedimentos técnicos, de formas de instrumentalização" definido por "governamentalidade política" (CASTRO, 2016, p. 191).

A governamentalidade é descrita por Foucault como "o encontro entre as técnicas de dominação exercidas sobre os outros e as técnicas de si" (FOUCAULT, 2001, p. 241) que se constituem na inter-relação de dois domínios. Considerando o propósito desse texto, vale destacar que, conforme Castro (2016, p. 190/191), o primeiro domínio pode ser descrito em três etapas:

(1) o conjunto construído pelas instituições, procedimentos, análises, reflexões, cálculos e táticas que permitem exercer essa forma de exercício do poder que tem, por objetivo principal, a população; por forma central a economia política; e por instrumento técnico essencial, os dispositivos de segurança; (2) a tendência, a linha de força que, por um lado, no Ocidente, conduziu à preeminência desse tipo de poder que é o governo sobre todos os outros: a soberania, a disciplina, e que, por outro, permitiu o desenvolvimento de toda uma série de saberes; (3) O processo, ou melhor, o resultado do processo pelo qual o Estado de justiça da Idade Média converteu-se, durante os séculos XV e XVI, no Estado administrativo e finalmente no Estado governamentalizado (grifo do autor).

Para realizar o cruzamento dos discursos, destacaremos as proposições elaboradas no Congresso de Milão tomando-as como fruto de formações discursivas que perpassam a história da Europa Moderna na produção de verdades sobre a normalização e correção dos corpos surdos.

Partindo da noção de biopolítica e tendo a política de verdade como pano de fundo, discutiremos as proposições elaboradas no referido congresso, considerando o desenvolvimento da medicina na França e na Alemanha - dois países que se destacam na discussão sobre os métodos mais importantes na educação de surdos e que direcionaram as discussões em Milão.

As discussões e reflexões que desenvolvemos neste texto subsidiam a perspectiva de que os discursos produzidos como verdades, a partir da Modernidade, para legitimar a normalização surda, se relacionam com as questões desenvolvidas na medicina social alemã e francesa do início do século XVIII que, delineadas no escopo da biopolítica, expressavam afiliação a um projeto maior, civilizacional, intelectual e ideológico.

Nos itens que se seguem, colocaremos em análise as biopolíticas produzidas por um regime de construção de verdades e problematizaremos, a partir da noção de noopolítica, o que contemporaneamente vivenciamos com o fortalecimento das identidades dos surdos.

Nesse esforço, problematizaremos a fabricação de formas de vidas surdas em um cenário/contexto marcado pela coexistência dos regimes de verdade hegemônicos da modernidade e de práticas discursivas que, constituídas no desencontro às modulações modernas, nos aproximam da condição da pluralidade e da diferença de se viver e se conduzir de outras formas. 


\section{CONHECER, NOMEAR E GOVERNAR: A MODULAÇÃo DE SUJEITOS (SURDOS) NA ERA DA VERDADE}

No período dominado pelo mercantilismo (entre o final do século XVI e começo do século XVII) houve a preocupação, nos países europeus, de se investir no estado de saúde da população. Foucault (2006) descreve a política mercantilista como uma prática que consiste essencialmente em majorar a produção de cada indivíduo ativo e, a partir daí, estabelecer fluxos comerciais que possibilitasse a entrada da maior quantidade possível de moeda no Estado (p. 82).

Os Estados franceses, ingleses e austríacos, nesse sentido, começaram a calcular a força ativa das suas populações (IBIDEM, IBID). Ao tomarmos os dois primeiros países como exemplo, notaremos o investimento em estatísticas de nascimento e mortalidade, bem como, a contabilidade, em massa, da população que aparece no século XVII e que se configuraram como dispositivos biopolíticos de conhecer, nomear e governar a população "[...] uma tecnologia que agrupa os efeitos de massas próprios de uma população [...]" (FOUCAULT, 1999, p. 297).

Foucault (2006, p. 80) destaca que o controle social que se exerce sobre os indivíduos não se estabelece na consciência ou na ideologia. Tal controle se opera pelo corpo e no corpo. Nas palavras do autor: “...Foi no biológico, no somático, no corporal que, antes de tudo, investiu a sociedade capitalista. O corpo é uma realidade bio-política. A medicina é uma estratégia bio-política".

Ademais, diferente da França e da Inglaterra, na Alemanha as ações para melhoria e controle da saúde da população contaram com um complexo sistema de saúde, denominado Medizinichepolizei - Polícia Médica (FOUCAULT, 2006). Para garantir a efetiva participação no nível de saúde da população, quatro principais técnicas foram empregadas, caracterizando a polícia médica em: (i) um sistema completo de observação da morbidade (e não apenas de taxas de natalidade e mortalidade) por intermédio de médicos atuando em diferentes níveis e regiões com registro dos diferentes fenômenos endêmicos e epidêmicos; (ii) a normalização da prática e dos saberes médicos. Nesse ponto, cabem algumas considerações feitas por Foucault (2006) ao descrever tal prática:

\footnotetext{
Procura-se deixar à universidade e sobretudo à própria corporação dos médicos o encargo de decidirem que consistirá a formação médica e como serão atribuídos os diplomas [...]. A medicina e o médico são, portanto, o primeiro objeto da normalização. Antes de aplicar a noção de normal ao doente, se começa por aplicá-la ao médico. O médico foi o primeiro indivíduo normalizado na Alemanha (FOUCAULT, 2006, p. 83).
}

Dando prosseguimento às atribuições da Polícia Médica, Foucault (2006, p. 83) ainda descreve outras duas características cruciais para garantir seu funcionamento, a saber: (iii) a criação de "[...] uma organização administrativa para controlar a atividade dos médicos" (p. 83) e, (iv) "[...] a criação de funcionários médicos nomeados pelo governo com res- 
ponsabilidade de uma região". Observamos, nessa terceira categoria, uma estratégia que objetivava centralizar as informações advindas dos saberes médicos sobre a população. Segundo Foucault, caberia a esse departamento especializado:

[...] acumular as informações que os médicos transmitem, ver como é realizado o esquadrinhamento médico da população, verificar que tratamentos são dispensados, como se reage ao aparecimento de uma doença epidêmica, etc., e, finalmente emitir ordens em função dessas informações centralizadas (FOUCAULT, 2006, p. 84).

É interessante notar, a partir desse ponto, a articulação entre o Estado e as ações médicas para legitimar a proposta de normalização. Esse fator é melhor evidenciado na quarta categoria de técnicas empregadas para validação dessas ações, em que encontramos, no começo do século XIX, um projeto adotado pela Prússia. Tratava-se de "[...] uma pirâmide de médicos, desde médicos de distrito que têm responsabilidade de uma população entre seis e dez mil habitantes, até os oficiais médicos, responsáveis por uma região muito maior [...]" (FOUCAULT, 2006, p. 84).

A figura do médico, já normalizada, passa a figurar não apenas como agente de extração e produção de saberes, mas como um "administrador de saúde" com práticas subordinadas "[...] um poder administrativo superior [...]". É importante notar que a integração dessas quatro técnicas pelo Estado alemão culmina em "[...] uma série de fenômenos inteiramente novos que caracterizam o que pode ser chamada a medicina de Estado" (FOUCAULT, 2006, p. 84).

Esse processo de normalização, característico do Estado alemão, não se difundiu por toda a Europa. Nesse sentido, Foucault (2006, p. 83) faz um contraponto entre a França e a Alemanha no quesito normalização e descreve que:

[...] na França, por exemplo, a normalização das atividades, no nível do Estado dirigiu-se, a princípio, à indústria militar. Normalizou-se primeiro a produção dos canhões e dos fuzis, em meados do século XVIII, a fim de assegurar a utilização de qualquer canhão em qualquer oficina, etc. depois de ter normalizado os canhões, a França normalizou seus professores.

Como podemos observar, existem percursos diferentes nos processos de normalização entre os alemães e franceses. Queremos chamar a atenção para a produção da "norma". Ewald (1993 apud VEIGA-NETO; LOPES, 2007, p. 956) chama-nos a atenção para o fato de que, nessa dinâmica, a norma funciona " [...] como um princípio de comparação, de comparabilidade, de medida comum, que se institui na pura referência de um grupo a si próprio, a partir do momento em que só se relaciona consigo mesmo".

Perspectivamos destacar que, pela via da normalização, as práticas sociais produziram domínios de saber, engendrando novos objetos, novos conceitos, novas técnicas e, também "[...] novas formas totalmente novas de sujeitos e de sujeitos de conhecimento" (FOUCAULT, 2002, p. 8). 
Desse modo, a normalização, como dispositivo construído discursivamente no contexto do Estado alemão moderno, operou como uma verdade que se estendeu até os congressos (e até mesmo a contemporaneidade), compondo assim o corpus de análise desse texto.

De fato, as atas do Congresso ${ }^{1}$ Internacional de Milão trazem várias informações marcantes sobre o que se tornaria a educação de surdos no final do século XIX e durante todo o século XX. Foram seis dias de discussões acerca de diversos temas e, por fim, foram aprovadas oito resoluções. Em primeiro lugar, foram discutidas as diferenças entre os métodos conhecidos sobre a educação de surdos: o Método de Articulação, Método de Sinais (com centralidade no sistema francês), Método Oral Puro, Método Combinado, Sinais Metódicos e Sinais Naturais. A forma de abordar tais métodos foi assim organizada:

1. Relate as vantagens do Método de Articulação em contraposição ao Método de Sinais e vice-versa (sobretudo levando-se em consideração o desenvolvimento mental e ressaltando sua importância no âmbito social).

2. Explique em que consiste o Método 'Oral Puro' e mostre a diferença entre este e o Método 'Combinado'.

3. Defina exatamente o limite entre os chamados Sinais 'Metódicos' e os 'Naturais'.

4. Qual é o meio mais natural e efetivo pelo qual os surdos-mudos poderão adquirir, sem dificuldade, sua própria linguagem?

5. Quando e como a gramática deve ser usada no ensino da linguagem? Deve ser usada a do oralismo ou a de sinais?

6. Quando os alunos deverão fazer uso de manuais ou livros? Em que disciplinas devem ser suprimidos? (ATAS, 1880 / 2011, p. 3-4).

Em consequência dessas questões, oito resoluções foram discutidas e aprovadas. Destacamos, a seguir, as três primeiras:

\section{O CONGRESSO:}

Considerando a incontestável superioridade da linguagem oral sobre a de sinais na reintegração do surdo-mudo à sociedade, permitindo a mais perfeita aquisição de conhecimento,

Declara:

Que se deve dar preferência ao Método Oral ao invés do método de sinais para a educação e ensino do surdo-mudo.

II O CONGRESSO:

Considerando que o uso simultâneo da língua oral e da língua de sinais oferece prejuízo à fala, à leitura labial e à precisão de ideias,

Declara:

1 Para este texto estamos usando a versão extraída das minutas oficiais em inglês apresentadas por A. A. Kinsey que estão traduzidas para o português. Trata-se do volume II da série histórica produzida no Instituto Nacional de Educação de Surdos, sendo esse o documento conhecido no Brasil. Vale ressaltar que o texto oficial das atas, redigido pelo secretário italiano do congresso, professor Pasquale Fornari (1837-1920), ainda não foi traduzido para a língua portuguesa e pode ser lido no original italiano ou na sua versão francesa. E também podemos encontrar outros relatórios como os de Adolphe Franck e de Ernest La Rochelle. 
Que se deve dar preferência ao Método Oral Puro.

III O CONGRESSO:

Considerando que um grande número de surdos e mudos não está recebendo o benefício da educação e que este fato se deve à falta de participação (impotenza) das famílias e das instituições.

Recomenda:

Que os governos tomem as medidas necessárias para que todos os surdos-mudos possam receber educação (ATAS, 1880 / 2011, p. 4-8).

Os direcionamentos preestabelecidos em Milão (1880), em sua introdução, já denotam que o objetivo desse congresso estava na discussão sobre qual método deveria ser empregado para a educação de surdos. E na terceira resolução, demonstra que o Estado passa a ser também responsável pela educação dos sujeitos surdos, ampliando assim, por meio da biopolítica, outras formas de subjetivação desses sujeitos.

Ressaltamos que buscamos evidenciar as condições de emergência que possibilitaram a formação do discurso sobre a primazia do Método Oral como regime de verdade que se desdobrou, no curso dos séculos seguintes, na fabricação de tipos específicos de ser surdo.

Aqui, conforme já anunciamos, o projeto de normalização do Estado alemão não se daria na esfera micro, apenas. A educação de pessoas surdas, sendo uma das pautas de debates nesse recorte histórico, também passaria por tecnologias de subjetivação capazes de trazer esses sujeitos para compor o atendimento ao que era estabelecido como norma.

Nesse ponto destacamos que, no escopo da Ciência Moderna, a norma é um conceito caro, uma vez que por intermédio dela (e outras técnicas) seria possível o ordenamento que, paradoxalmente, se dá no caos. Assim, "[...] o caos é condição necessária à ordem; essa só é ela mesma, isso é, ela só se identifica com ela mesma se for colocada frente a frente com o seu outro, que é o caos" (VEIGA-NETO; LOPES, 2001, p. 26).

Destarte, o congresso de 1880 tornou-se um espaço profícuo para o embate dos métodos para a educação de surdos. Todavia, para validação dessa verdade, alguns critérios foram seguidos a fim de estabelecer aquilo que Foucault (1996) denominou de episteme da ordem.

Trabalhar com a verdade de um método, considerando-o superior, exigiu dos participantes uma articulação com outros campos de conhecimento dos quais a medicina se apropriou e, para esta reflexão, nos ancoramos nas contribuições apresentadas por Michel Foucault nas conferências As verdades e as formas jurídicas (1973) proferidas na Pontifícia Universidade Católica do Rio de Janeiro.

De acordo com o autor, a primeira forma (bastante arcaica) de produzir a verdade é o lançamento do desafio entre adversários. Esse procedimento judiciário grego foi utilizado devido à contestação entre Antíloco e Menelau durante a realização dos jogos de corrida de carros, sendo o primeiro deles vencedor do desafio. Embora fosse designado um responsável para controlar a regularidade do jogo, este não foi utilizado para se posicionar com relação à acusação de Menelau contra Antíloco. Nesse caso, Menelau propõe um desafio para solucionar o problema da irregularidade, que é retratado da seguinte maneira: 
[...] Põe tua mão direita na testa do teu cavalo; segura com a mão esquerda teu chicote e jura diante de Zeus que não cometeste irregularidade. Nesse momento, Antíloco, diante deste desafio que é uma prova (épreuve), renuncia à prova, renuncia a jurar e reconhece que cometeu irregularidade (FOUCAULT, 2002, p. 32).

Notamos que o modo de produção de verdades, característico da sociedade grega, não se dá via inquérito ou investigação do ocorrido, mas se estabelece pelas vias do jogo de prova. Essa maneira de conduzir a verdade será ressignificada, séculos depois, como narrado na tragédia grega Édipo-Rei que, neste caso, entra em cena um novo componente, a testemunha.

Eis a segunda maneira descrita para a produção e validação da verdade, em que a própria soberania do rei é questionada (FOUCAULT, 1973).

Ao analisar o modo de estabelecer a verdade em Édipo, Foucault (2002, p. 34) sugere que esse mecanismo "[...] obedece inicialmente uma lei, uma espécie de pura forma, que poderíamos chamar de lei das metades".

A testemunha é o elemento que determina, constrói e valida a verdade. Essa forma de constituição das partes fica também evidente no Congresso de Milão, quando pessoas de diferentes segmentos (familiares, médicos, professores etc.) são convidadas a narrarem o sucesso obtido na educação de pessoas surdas utilizando o método oral.

Especialmente na Alemanha e na França, os "avanços" de saberes, conforme destacamos, estavam relacionados à prevenção de doenças devido ao crescimento das cidades e às precárias condições de vida da classe operária. No século XIX, o que fora produzido sobre os surdos e a surdez se destacou. Em Milão, ficou determinada a condição de treinamento oral para os surdos associando-se, pela primeira vez, a surdez como um problema de saúde, inclusive de ordem psi (WITCHS; LOPES, 2018).

Assim, a invenção da surdez e da deficiência auditiva (LOPES, 2011) passou a ser incorporada entre os saberes médicos e educacionais, exigindo que as escolas passassem a trabalhar com o método oral puro (WITCHS; LOPES, 2018).

Não nos deteremos na análise das narrativas dessas testemunhas, pois esse procedimento fugiria ao escopo deste trabalho. Dessa forma, sigamos conduzindo a escrita de modo a tecer considerações acerca da produção de verdades sobre os sujeitos surdos do nosso tempo e como essa constituição identitária do surdo é fruto de uma formação discursiva historicamente construída.

O regime de verdade produzido sobre as pessoas surdas fundamenta-se na perspectiva de que esses poderiam (e deveriam) ser educados. Escapando à possibilidade de fazer a defesa de um método ou de outro para ser utilizado na educação de pessoas surdas, neste trabalho, utilizamos a expressão cunhada por Veiga-Neto e Saraiva (2011), compreendendo, portanto, o educar como arte de governar.

Há, todavia, alguns entraves nesse processo de modulação, e, em se tratando do público surdo (minoria linguística) em específico, foi pelo viés da linguagem que se fez necessário agenciamentos para produzir um surdo. Por minorias, seguimos aquilo que descrevem Deleuze e Gattarri em Mil Platôs (1997), quando alertam que estas não se definiam neces- 
sariamente pelo pequeno número, mas pelo devir ou flutuação, ou seja, pelo desvio que as separa deste ou daquele axioma que constitui uma maioria redundante.

Pensando a constituição de verdades que modulam formas de vidas surdas como uma invenção da Modernidade, "forjada na necessidade social e política de participação de todos" (RECH, 2010, p. 28), tecemos a compreensão de que precisamos conceber a fabricação de subjetividades surdas como um empreendimento que teve sua emergência a partir do século XVIII e carrega até hoje características de formações discursivas anteriores e continua se proliferando como regimes de verdade do nosso tempo.

\section{NoOPOLÍTICA E MODULAÇõES DE SUBJETIVIDADES EM REGIMES DE PÓS-VERDADE}

O elemento que selecionamos para prosseguir com as análises foi nomeado por Deleuze (1990/1992) de sociedades de controle. Segundo Hur (2013), "esta discussão remete a uma redefinição, de forma sintética e original, do conceito de biopolítica de Foucault" (p. 210). Essa descontinuidade foi amplamente discutida por Lazzarato (2006), que desenvolveu a noção de noopolítica como forma de compreender a modulação de condutas a partir dos desejos e dos pensamentos. De acordo com o autor:

\footnotetext{
A noopolítica (ou conjunto das técnicas de controle) se exerce sobre o cérebro, implicando em princípio a atenção, para controlar a memória e sua potência virtual. A modulação da memória seria então a função mais importante da noopolítica. Se as disciplinas moldavam os corpos constituindo hábitos principalmente na memória corporal, as sociedades de controle modulam os cérebros e constituem hábitos principalmente na memória espiritual (LAZZARATO, 2006, p. 100 , tradução dos autores).
}

Nesse sentido, no contexto das sociedades de controle, a modulação dos corpos se constitui e é assegurada pelos (i) dispositivos de disciplina (fábricas, escolas, prisões, manicômios), (ii) a gestão da vida organizada pelo biopoder (políticas de saúde, estado de bem-estar etc.) e (iii) a modulação da memória e suas potências virtuais reguladas pela noopolítica (ondas hertzianas, constituição da opinião pública, da percepção e modos de pensamentos coletivos). "Os efeitos desse processo é que o 'funcionamento' de pensamento propagado pelo aparelho de captura segue a gramática neoliberal" (HUR, 2013, p. 211).

Noo vem do radical grego nous, que etimologicamente significa pensamento, mente. Portanto, consiste no fenômeno de controle e gestão da vida que se pauta na modulação do pensamento. Desse modo, o poder não opera apenas sobre a matéria, mas também sobre aquilo que é denominado como imaterial, a consciência, o pensamento e a subjetividade.

Vale ressaltar que os três elementos supracitados se constituíram em diferentes períodos e não são substituídos uns pelos outros, mas se agenciam para o estabelecimento da sociedade de controle.

É nesse contexto que a noção de pós-verdade se apresenta como um elemento que se caracteriza pela proliferação de discursos. Devido aos constantes usos, sobretudo no meio 
digital, e por ter atraído grande interesse, a palavra foi eleita pelo Dicionário Oxford no ano de 2016 e é definida da seguinte maneira: "relativo a ou que denota circunstâncias nas quais fatos objetivos são menos influenciadores na formação da opinião pública do que apelos à emoção ou à crença pessoal" (tradução dos autores).

No vídeo divulgado pela editora responsável pelo dicionário, o conceito de pós-verdade existe desde a década passada, mas o Dicionário Oxford viu um pico de frequência este ano no contexto do referendo da União Europeia no Reino Unido e da eleição presidencial nos Estados Unidos. Ele também se tornou associado a um substantivo, em particular, na frase política pós-verdade.

Tomamos, nesse texto, a política de pós-verdade como uma noção que, junto à noopolítica, contribuem para compreender que os agenciamentos do nosso tempo, além de passarem por um refinamento, que é característico das sociedades de controle, fabricam modos específicos de se constituir sujeito. Os discursos que criam, modulam e direcionam os modos de vidas surdas contemporâneas, portanto, carecem também de um deslocamento analítico que contemple a matriz de funcionamento do pensamento (DELEUZE \& GUATTARI, 1997).

Começaremos pela conferência intitulada "Por uma forma de vida surda: sua existência basta" ${ }^{2}$ quando a professora e pesquisadora Maura Corcini Lopes abordou a concepção de vidas surdas para além da materialidade da surdez inscrita sobre o corpo, ou, nas palavras da referida autora: "[...] significa compartilhar com aqueles que são semelhantes um conjunto de práticas, de saberes que acabam constituindo uma forma de vida em luta" (LOPES, 2018, p. 18).

Esse tipo de análise contribui para a abertura de caminhos distintos a fim de problematizar como as normativas predeterminadas para a fabricação do sujeito moderno têm se multiplicado na contemporaneidade. Pontuaremos, a partir da noopolítica como noção e da pós-verdade como vetor, duas análises realizadas por surdos pesquisadores que contribuem para a compreensão da produção de subjetividades.

A primeira delas diz respeito às descontinuidades históricas que contribuíram/contribuem para a hipervalorização de um jeito específico de ser surdo. Nessa análise, a partir das práticas de integração e, posteriormente com o imperativo da inclusão, Vieira (2016) observa que os modos de vidas surdas são produzidos e gerenciados pelo Estado e se relacionam ao regime de verdade vigente de determinado tempo.

Fazendo uma relação entre o movimento da integração escolar ${ }^{3}$ e a surdez, entendo que o modelo ideal de cidadão deficiente auditivo almejado pelo Estado naquele momento era aquele sujeito que poderia ser transformado o mais próximo possível do padrão de normalidade ouvinte (VIEIRA, 2016, p. 100).

2 Disponível em: $<$ http://cameraweb.ccuec.unicamp.br/watch_video.php? $\mathrm{v}=\mathrm{MS} 8 \mathrm{~S} 7 \mathrm{SK} 16 \mathrm{KBO}>$. Acesso em nov. 2018.

3 Para Rech, "a ideia inicial - que sustentou o princípio da integração escolar - foi de normalizar, ou seja, fazer com que as pessoas consideradas "diferentes" tivessem oportunidade de se tornar parecidas com o modelo ideal de cidadão" (RECH, 2010, p. 100). 
Para a autora, num dado momento da História as políticas de integração desses sujeitos produziram um tipo hipervalorizado de ser surdo, qual seja, o surdo oralizado. Nesse contexto, "Era comum na instituição que os deficientes auditivos cantassem o hino nacional, rezassem o pai nosso e, mesmo sem entender o significado do que estava sendo 'falado"' (VIEIRA, 2016, p. 100-101, grifo da autora). Ainda no contexto das políticas de integração "a escola estava equipada com materiais destinados ao treinamento da fala dos alunos deficientes auditivos para estimular a sua oralização" (VIEIRA, 2016, p. 102).

Em outro momento da História, um novo modo de modulação dos sujeitos surdos serviu como vetor para o agenciamento do modo contemporâneo de vidas surdas: o sujeito surdo bilíngue. Segundo Vieira (2016), a emergência da inclusão a questão da normalização desses sujeitos é reconfigurada como um imperativo. Nesse contexto, "a partir da década de 1990, a comunidade surda iniciou uma mobilização em busca do reconhecimento de sua língua, a Libras" (VIEIRA, 2016, p. 107). A partir das mobilizações, Vieira (2016) pontua uma série de dispositivos (documentos, leis e decretos) que contribuíram para a constituição de uma forma de condução:

\footnotetext{
$\mathrm{Na}$ esteira dessas discussões em torno da Língua Brasileira de Sinais, foi elaborada a Lei 10.436/2002 que legalizou e reconheceu a Libras como língua oficial da população surda brasileira, sendo regulamentada anos depois por meio do decreto 5.626/2005. A partir do reconhecimento da Libras foram produzidos discursos em busca de uma efetivação da educação bilíngue, baseada numa proposta que possibilitava o surdo ser conduzido pela sua diferença cultural e pelo domínio da Língua Brasileira de Sinais (VIEIRA, 2016, p. 108).
}

Assim, a partir das determinações provenientes dos dispositivos supracitados, houve mudanças gradativas na maneira de educar e, por conseguinte, governar os sujeitos surdos. Como exemplos, a autora traz a substituição da estrutura pedagógica a começar pelos professores, pois "tendo como referência a condição bilíngue do surdo Os professores passaram então a ser substituídos gradativamente por não se adaptarem à proposta bilíngue adotada pelo Estado a partir da emergência da inclusão" (VIEIRA, 2016, p. 108).

A segunda análise, que nos é cara, foi realizada por Carvalho (2016). O enfoque da problematização recaiu sobre a formação de surdos professores. $\mathrm{O}$ autor evidencia os perigos de se constituir o sujeito docente a partir da materialidade da surdez inscrita no corpo surdo. Tal empreendimento necessitou de um mergulho no que nomeamos por ser humano e como chegamos a ser quem somos.

Para o autor, a noção de formação do sujeito precisa ser vista para além dos paradigmas forjados nos regimes de verdade da modernidade, haja vista que as formações discursivas do que significa ser surdo carrega a herança iluminista do que quer dizer ser humano. Logo, "A norma da humanidade é - uma norma do que significa ser humano e, ao fazê-lo, exclui aqueles que não vivem ou são capazes de viver de acordo com essa norma" (CARVALHO, 2016, p. 131). 
Um ponto que gostaríamos de destacar no estudo realizado por Carvalho (2016) é a necessidade do surdo educador, ou o surdo professor como educador, sendo este visto como "parteiro", indivíduo de quem a tarefa é liberar o potencial racional do ser humano. $\mathrm{Na}$ conclusão do trabalho, temos uma passagem que sintetiza esse argumento:

\begin{abstract}
A educação é um espaço onde os indivíduos únicos tornam-se presença "por meio de suas relações com os outros que não são como eles”. Dessa maneira, só podemos nos tornar presença num mundo povoado por outros que não são como nós. Biesta (2013, p. 26) compreende o mundo como um mundo de pluralidade e diferença que não é abarcado pela inclusão, uma vez que esta está muito mais próxima do que se compreenderia como socialização do que das ideias de pluralidade e de diferença (CARVALHO, 2016, p. 132).
\end{abstract}

É nesse sentido que, para nós, ao criar condições que vão em desencontro às modulações modernas que estabelecem o ser surdo, ser humano ou ser brasileiro, aproximando-os da condição da pluralidade e da diferença de se viver e se conduzir de outras formas, as vidas surdas se libertam dos regimes hegemônicos produzidos.

A esse respeito, cumpre observar que, paradoxalmente, se por um lado os regimes de verdades contribuíram para a produção do deficiente auditivo, convencendo-o de sua capacidade e anormalidade, por outro, também ajudaram a produzir no surdo a inteligência e a capacidade de comunicação e aprendizagem (WITCHS; LOPES, 2018).

Se, por um lado - nos séculos XIX e XX -, os saberes sobre a surdez como anormalidade enfatizaram a invenção das próteses e do implante coclear (VIEIRA, 2016), da imposição da língua portuguesa (WITCHS, 2014), da negação do outro surdo (CARVALHO, 2016), de práticas de correção, por outro - no final do século XX e nas duas primeiras décadas do século XXI - os saberes sobre a surdez como diferença étnica, associados à condição da pluralidade e da diferença de se viver e se conduzir de outras formas, possibilitaram o fortalecimento das identidades e dos surdos, bem como, da língua brasileira de sinais (WITCHS; LOPES, 2018). Esse cenário/contexto evidencia a impossibilidade da manutenção dos regimes de verdade hegemônicos da modernidade.

Nesse sentido, vivenciamos um deslocamento de ênfases, de uma política de verdades em direção a políticas de pós-verdades. Incluímos aqui a percepção de que, na contemporaneidade, essas práticas discursivas que vão em desencontro às modulações modernas, coexistem em formatos de práticas que podem ser vistas sobre uma grade de inteligibilidade neoliberal, que promovem, entre outras coisas, a exaltação das diferenças traduzidas em identidades (LOPES, 2015).

Desse modo, especialmente no escopo do regime neoliberal, temos a emergência de práticas que incentivam a vigilância do (a)normal e a proliferação do politicamente correto (LOPES, 2015). Agora as lutas surdas se constituem por distintas variáveis ou paradigmas (GESSER, 2008), (LOPES, 2015). Nesse cenário, questões sobre como nomear os sujeitos - surdo ou deficiente auditivo? - tornam-se terrenos de intensas discussões que recorrem aos regimes de verdade produzidos na modernidade. 
Observamos, assim, que a luta pelos encontros se mantém (LOPES, 2015) e é materializada em discursos como "eu sou surdo" e "sou o exemplo para os alunos surdos e a comunidade surda" (CARVALHO, 2016). Há, todavia, uma consonância com os discursos identitários da garantia dos direitos individuais que são fortemente difundidos pelas políticas de inclusão (RECH, 2010), (LOPES, 2015).

No interior dessas formações discursivas, a identidade surda (PERLIN, 1998, 2004) oferece subsídios para a fabricação de subjetividades específicas para a constituição de modos de vida surda que se autoidentificam nas categorias pré-formuladas, se distinguem e até se excluem.

\section{CONSIDERaÇões FINAIS}

As pontuações deste texto se encerram aqui, mas não as reflexões em que o mesmo se debruçou. Retomar o "Congresso de Milão" para fazermos análises de outra ordem exigiu-nos um olhar minucioso e despido de preconcepções a ele designadas.

Fizemos a escolha de olhar para ele como um documento-monumento "[...] onde se decifravam os rastros deixados pelos homens, onde se tentava reconhecer em profundidade o que tinham sido [...]" (FOUCAULT, 2005, p. 8).

Ao escolhermos caminhar em volta desse documento-monumento, nos ativemos às produções de verdades que modulam vidas surdas. Assim, partimos da grade de inteligibilidade da governamentalidade para olharmos a biopolítica como conjunto de tecnologias que produzem verdades que constituem esses sujeitos enquanto sujeitos sociais.

E decidimos ir em direção à noopolítica como efeito das políticas de produção de pós-verdades que modulam, em nossa contemporaneidade, as vidas surdas a partir das marcas identitárias produzidas coletivamente por esses sujeitos.

Finalizamos, por ora, esta discussão, apontando que existe uma norma flexível na contemporaneidade que se dilui, por meio dos discursos identitários, para cada grupo (minoritário) social. Nesse contexto de multiplicação de normalidades, torna-se mais difícil reconhecer as fronteiras existentes entre o normal e o anormal, o que põe em risco ou mesmo torna por demais complexo o discernimento daquilo pelo qual lutamos ou refutamos.

\section{REFERÊNCIAS}

CARVALHO, D. J. Não basta ser surdo para ser professor: as práticas que constituem o ser professor surdo no espaço da inclusão. Dissertação (mestrado) - Universidade Federal do Espírito Santo. Programa de Pós-Graduação em Educação, Vitória, 2016.

DELEUZE, Gilles \& GUATTARI, Félix. Mil Platôs: Capitalismo e Esquizofrenia, v. 5. São Paulo: 34, 1997. 
FOUCAULT, Michel. A ordem do discurso, 17. ed. São Paulo: Edições Loyola, 1996.

. A Hermenêutica do Sujeito. Trad. bras. de M. A. Fonseca e S. T. Muchail. São

Paulo: Martins Fontes, 2004.

. A Arqueologia do Saber, 7. ed. Rio de Janeiro: Forense universitária, 2005.

. Microfísica do poder. Rio de Janeiro: Edições Graal, 2006.

GESSER, Audrei. Do patológico ao cultural na surdez: para além de um e de outro ou para uma reflexão crítica dos paradigmas. Trab. linguist. apl. [on-line], 2008, v. 47, n. 1, p. 223-239.

HUR, Domenico Uhng. "Da biopolítica à noopolítica: contribuições de Deleuze." Lugar comum, n. 40, p. 201-215, 2013. Disponível em: <http://uninomade.net/wp-content/files mf $/ 111012130335 \mathrm{Da} \% 20$ biopol $\% \mathrm{C} 3 \% \mathrm{ADtica} \% 20 \% \mathrm{C} 3 \% \mathrm{~A} 0 \% 20$ noopol\%C3\%ADtica\%20contribui\%C3\%A7\%C3\%B5es\%20de \%20Deleuze $\% 20$-Domenico $\% 20$ Hur.PDF $>$. Acesso em: 18 jun. 2019.

LAZZARATO, Maurizio. "Para uma definição do conceito de 'bio-política'." Lugar Comum, Rio de Janeiro, RJ, n. 05-06, p. 81-96. 1999. Disponível em: < http://uninomade. net/wp-content/files_mf $/ 111712120656$ Para $\% 20$ uma $\% 20$ defini $\% \mathrm{C3} \% \mathrm{~A} 7 \% \mathrm{C} 3 \% \mathrm{~A} 3 \mathrm{o} \% 20$ do $\% 20$ conceito $\% 20$ de $\% 20$ biopol $\%$ C3\%ADtica $\% 20 \%$ E2\%80\%93\%20Maurizio\%20Lazzarato.pdf.> Acesso em: 10 jun. 2019. ISSN 1415-8604.

. Políticas del acontecimiento. Buenos Aires, Argentina: Tinta Limón ediciones, 2006.

LOPES, Maura C. Surdez \& Educação, 2. ed. Belo Horizonte: Autêntica, 2011 (Pensadores \& Educação / Temas \& Educação).

PERLIN, Gladis. "Identidades Surdas.” In: C. Skliar (Org.). A Surdez: um olhar sobre as diferenças. Porto Alegre: Editora Mediação, 1998.

PERLIN, Gladis. “O Lugar da Cultura Surda.” In: THOMA, Adriana da Silva e LOPES, Maura Corcini (Orgs.). A Invenção da Surdez: Cultura, alteridade, Identidade e Diferença no campo da educação. Santa Cruz do Sul: EDUNISC, 2004.

RECH, T. L. A emergência da inclusão escolar no governo FHC: movimentos que a tornaram uma - verdade que permanece. Dissertação (Mestrado em Educação) Programa de Pós-Graduação em Educação, Universidade do Vale do Rio dos Sinos, São Leopoldo, 2010.

VEIGA-NETO. A. “Governo ou Governamento.” Currículo sem Fronteiras, v. 5, n. 2, p. 79-85, jul./dez. 2005. 
. "Na oficina de Foucault.” In: GONDRA, José; KOHAN, Walter (Org.). Foucault 80 anos. Belo Horizonte: Autêntica, 2006, p. 79-91.

. "Inclusão e governamentalidade.” Educ. Soc. Campinas, v. 28, n. 100 - Especial, p. 947-963, out. 2007.

VIEIRA, Eliane T. de B. Práticas de hipervalorização de diferentes modos de ser surdo no contexto educacional do Centro de Capacitação de Profissionais da Educação e de Atendimento às Pessoas com Surdez (CAS) no Estado do Espírito Santo. Dissertação (Mestrado) - Universidade Federal do Espírito Santo. Programa de Pós-Graduação em Educação, Vitória, 2016.

WITCHS. P. A educação de surdos no estado novo: práticas que constituem uma brasilidade surda. Dissertação de mestrado. Universidade do Vale do Rio dos Sinos. Programa de pós-graduação em Educação. São Leopoldo, RS, 2014.

. Governamento linguístico em educação de surdos: práticas de produção do Surdus mundi no século XX. Tese de doutorado. Universidade do Vale do Rio dos Sinos. Programa de pós-graduação em Educação. São Leopoldo, RS, 2018.

. LOPES, M. C. "Forma de vida surda e seus marcadores culturais.” Educ. rev. [on-line], 2018, v. 34, e 184713. Epub 27 - ago. 2018.

Dados dos Autores:

Lucyenne Matos da Costa Vieira-Machado

Estágio pós-doutoral em Educação pela Universidade Vale do Rio dos Sinos. Porto Alegre/ RS-Brasil. Professora da Universidade Federal do Espírito Santo. Vitória/ES - Brasil. lumatosvieiramachado@gmail.com.

\section{Reginaldo Célio Sobrinho}

Pós-Doutor pela Universidade Federal da Grande Dourados. Mato Grosso do Sul/MSBrasil. Professor da Universidade Federal do Espírito Santo. Vitória/ES-Brasil. rsobrinho2009@hotmail.com.

\section{Cássio Pereira Oliveira}

Mestrando do Programa de Pós-Graduação em Educação pela Universidade Federal do Espírito Santo. Vitória/ES-Brasil. cassio.tils@gmail.com.

Submetido em: 17-7-2019

Aceito em: 27-11-2019 